\title{
MULTICULTURALISM AND History Education: Teachers' Perceptions
}

\author{
Nikolaidou Charis ${ }^{1}$ and Repoussi Maria ${ }^{2}$ \\ ${ }^{1} \mathrm{PhD}$ candidate, Aristotle University of Thessaloniki, Thessaloniki, Greece \\ ${ }^{2}$ Professor of History and History Education, \\ Aristotle University of Thessaloniki, Athens, Greece
}

\begin{abstract}
The present paper attempts to explore the perceptions and views of public primary school teachers in the city of Thessaloniki on multiculturalism and historical education. In particular, the involvement of teachers in the implementation of intercultural practices was studied, while specifically the history course was chosen since on one hand it gathers many identical features and on the other hand it is offered for the design and implementation of many intercultural interventions. The city of Thessaloniki with its multicultural past was used as a basis for outlining the trends and views of the human resources that serve education. The sample of the research consisted of 413 teachers from the primary schools of the prefecture of Thessaloniki. The quantitative methodological approach was followed and the data were collected using a questionnaire. The results of the research showed that the teachers' training in matters of intercultural education is incomplete, a fact that affects their perceptions and their intercultural practices in a negative way. The research also showed that history curricula are in need of great changes in respect to integrate the multicultural perspective.
\end{abstract}

\section{KEYWORDS}

Intercultural education, perceptions, local history, Thessaloniki.

\section{INTRODUCTION}

In recent years, the huge increase in migration and refugee flows to the West has led to an increase in Western societies' population and cultural diversity. In most countries of the western world, even those from which the people migrated, there are now populations that coexist with different cultural, religious, and ethnic characteristics, both in society and in the classrooms. This multicultural reality raises the issue of multicultural and intercultural education, since, as evidenced by relevant researches, issues of exclusion, discrimination and inequality arise very often (Au, 2017, Chorozoglou, 2011). These issues can be effectively addressed through the adoption of intercultural education principles. A basic principle of this intercultural education is the collective consciousness, which transcends the group boundaries, respects each culture and considers diversity as an asset (Tremblay, 2019). In this regard, the role of the teacher is considered crucial, since he is called to manage the cultural diversity of the classrooms in combination with the problems he faces in the educational practice. On the occasion of the above questioning, the research interest focuses on the attitudes and representations of teachers regarding multiculturalism and acculturation. These attitudes and perceptions play a decisive role in the pedagogical relationship and practice, as they affect the expectations that teachers themselves form regarding their students' school performance, thus leading to the formation of the corresponding attitude towards them and finally determining the extent in which they implement contemporary intercultural practices. According to the review of the bibliography in 
relevant researches conducted in recent years on primary education, it is observed that teachers in order to meet the challenge of multiculturalism, they need to receive relevant training, which can be developed through professional developing programs in regional and school level providing support and guidance in the implementation of intercultural education (Luft, 1997, Winitzky \& Barlow, 1998, HO, 2001, DeJaeghere \& Cao, 2009). In fact, according to Sales, Traver, \& Garcia (2011) intercultural education programs for teachers have helped them become more aware of their personal responsibility to create an intercultural educational environment free of exclusions and discrimination. Typically, teachers who participated in this training educational program began to integrate methods of collaborative learning in the educational process, more often, while developing cooperation with the students' parents in order to achieve school change. Furthermore, the study of Atiles, Douglas, and Allexsaht-Snider (2017) showed that some personality traits in teachers, such as progressiveness, are considered very important, as they are associated with the intention and ability of implementing intercultural education strategies. In particular, many studies note in their results that the application of intercultural education during the educational practice requires an open mind, self-knowledge, sociability, democracy, tolerance and calmness (Garmon, 1998, Race, 2011: 96, Polat \& Metin, 2012, Pérez, et al., 2017). In fact, another study argues that teachers who adopt stereotypes do not show multicultural self-efficacy, since these stereotypes subconsciously affect their educational work and are likely to contribute negatively to children's cognitive and emotional development (Reyna, 2000). In addition, according to studies that concern the attitudes and perceptions of teachers about multiculturalism, it seems that they themselves characterize teaching in a multicultural classroom as difficult and demanding (Igglesi, 1997, Nikolaou, 2003). However, they do not seem to be dominated by negative views and attitudes towards children of different nationalities while at the same time they show interest and have a positive view on intercultural education (Nikolaou, 2000, Zotou, 2017, Samanta Angelopoulou \& Manesis, 2017). Furthermore, the presence of non native speakers and foreign children is judged by the majority of teachers not only as an acceptable reality, but as a positive condition, typically citing the inflexible national curriculum as an obstacle that limits their autonomy (Govaris \& Andreadakis, 2002, Patinari, 2015). The results of the research of Huang et al. (2017) on the perceptions of the science teachers of primary education showed that teachers, while presenting positive perceptions about multiculturalism and its promotion in their teaching, in practice they did not apply methods and activities of intercultural education. The purpose of this research initially, is to explore and record teachers' views and perceptions about interculturalism. It also aims to intersect these perceptions with the choices made by teachers in teaching practice. The history of the city of Thessaloniki, which is a crossroads city of East and West that preserves the traces of the coexistence of different communities with different cultures, different religions and languages, was selected in this research to determine whether teachers use the multicultural history of Thessaloniki in order to promote intercultural values among their students.

\section{Materials AND Methods}

The quantitative method with the corresponding tool, the questionnaire, was used to investigate the research questions. Quantitative research was chosen because the concepts under study are measurable, so it is possible to measure the degree of agreement on specific questions, in an objective way, using Likert scale questionnaires (Bell, 2001). In fact, for the study of attitudes and perceptions, the use of questionnaires is considered the most popular method (Vamvoukas, 1991, Verma \& Mallick, 2004). The conditions of the pandemic were also prohibitive for the adoption of qualitative or mixed - quantitative and qualitative - methods which were in our original research intention. The reference population of the research is the teachers of general classes, branch PE70 public schools and not of supplementary teaching, parallel support, Special Education or intercultural schools. It also includes all forms of professional engagement with the Ministry of Education and Religious Affairs (permanent or temporary teachers, hourly wage or 
newly appointed teachers). The geographical area of the sample is the prefecture of Thessaloniki, that is, all the schools that belong to the two Directorates of Primary Education, those of Eastern and Western Thessaloniki. Specifically, the Directorate of Primary Education of Eastern Thessaloniki includes the schools of the center (Municipality of Thessaloniki) and those of the districts in the eastern part of the city (Municipalities of Kalamaria, Pylaia-Chortiatis, Thermi and Thermaikos), those districts that gather middle and upper financial status. The Directorate of Primary Education of $\mathrm{B}^{\prime}$ Thessaloniki extends to the west of the city and specifically to the Municipalities of Ampelokipi - Menemeni, Volvi, Delta, Kordelio - Evosmos, Lagada, Neapolis Sykies, Pavlou Mela, Chalkidona and Oreokastro, districts with low financial status. The questionnaires were sent via e-mail and a special Google form platform through which the respondents fill in and submit their answers automatically. The electronic questionnaires were sent to the e-mails of all the general primary schools of the prefecture of Thessaloniki, being in operation during the school year 2020-2021. The e-mail addresses were retrieved from the primary education Directorates of Eastern and Western Thessaloniki. Therefore, according to the data provided by the Directorates of Education, the questionnaire was sent to one hundred and thirty five (135) schools in Eastern Thessaloniki and to one hundred and seventy four (174) schools in Western Thessaloniki. Thus, in the prefecture of Thessaloniki, seven thousand one hundred and thirty three $(7,133)$ permanent and temporary teachers of the branch PE70 $(4,480$ in Eastern Thessaloniki and 2,653 in Western Thessaloniki). The completed questionnaires we received are four hundred and thirteen (413) and constitute $6 \%$ of the general population. The questionnaire consists of four different groups of questions, each of which concerns the investigation of different attitudes, perceptions and information. More specifically, the questions are classified in terms of content in the following topics: a) demographics (7 questions), b) interculturalism (13 questions), c) historical education (17 questions) and d) local history (21 questions). The issue of multiculturalism that concerns the questionnaire is considered very important, since the attitudes and views of teachers on it determine the degree to which they implement modern intercultural practices. The research interest also focuses on teachers' views on school history, as this subject can be a productive and creative field of application of the basic principles and axioms of intercultural education. In particular, four open-ended questions were asked, which enable respondents to express themselves freely, to identify the broader context that represents them, and to enable the researcher to create an interpretive framework for drawing conclusions. The technique of qualitative content analysis is applied to these questions, so that the qualitative data given to us by the open-ended questions can be quantified and analyzed appropriately. Then, closed questions were asked, which are suitable for large-scale researches, as they offer easy coding, sorting and editing. Close-ended questions, although restricting the freedom of the participants, examine the issue in question in a broader and more representative way (Kyriazi, 2002). In these questions, two five-point scales of possible positions were used, Likert-type answers with the following grades: Strongly disagree, Disagree, neither agree nor disagree, Agree, Strongly agree and Not at all, Very little, A little, Very important Very much important. We also have multiple choice questions, in which the respondent can choose one or more of the suggested answers, and even add his / her personal opinion by choosing another. Regarding the weighting of the questionnaire, its composition was carried out after a study of relevant research in the international literature, communication and contact with teachers dealing with issues of interculturalism and local history, who through the data they gave us, the first draft of the questionnaire emerged. The reliability assessment was done with repeated measurements and more specifically, through a pilot study pre-test on thirty participants of the population. This application was a preliminary assessment of the validity and reliability of the questionnaire, with the aim of correcting as many errors and omissions as possible. The test mainly concerned the level of comprehensibility and correct wording of the questions, the time of completion, the interest of the respondents and the appearance of the questionnaire. The corrections led to a new improved questionnaire, which was subsequently submitted to a new pilot test-retest study. The final weighting of the questionnaire includes the electronic distribution of the improved 
questionnaire in the same sample two consecutive times in a limited period of time (in fifteen days) and under the same conditions. In this case the stability of the answers was evaluated through the statistical correlation between the two scores. The processing of the results of this questionnaire demonstrated the definite validity and reliability of the research tool queries. The questionnaire created consists of four different groups of questions, each of which concerns the investigation of different attitudes, perceptions and information. In particular, it includes questions about demographics, interculturalism, historical education and local history.

\section{RESULTS AND DISCUSSION}

Investigating the findings, led us to various results, in this work as some of them are presented. The graphs below are crucial and are mainly those that led to the valid support of the conclusions which in turn will be reported in the next chapter. Initially, the answers given by the teachers describing what intercultural education is, show that more emphasis needs to be placed on these issues during the university education, as half of the respondents were not prepared to clearly identify intercultural education and especially to mention the range of its importance. In particular, $50.5 \%$ of the respondents identified intercultural education in terms that do not correspond to the relevant international bibliography. In particular, $26.2 \%$ defined intercultural education as the integration of foreign students and $24.3 \%$ as education aimed at children from different national and cultural backgrounds. While, according to the fundamental principles of intercultural education, it aims neither at the integration, nor at the assimilation of foreigners in the dominant society and is clearly addressed to the whole number of students, not only foreigners, but also natives. Closer to what is defined by the international and domestic bibliography as truly intercultural education, it was found that $26.2 \%$ who consider intercultural education aimed at combating stereotypes (antiracism education) and $21.1 \%$ as education without segregation and discrimination.

\section{What is Intercultural Education according to you?}

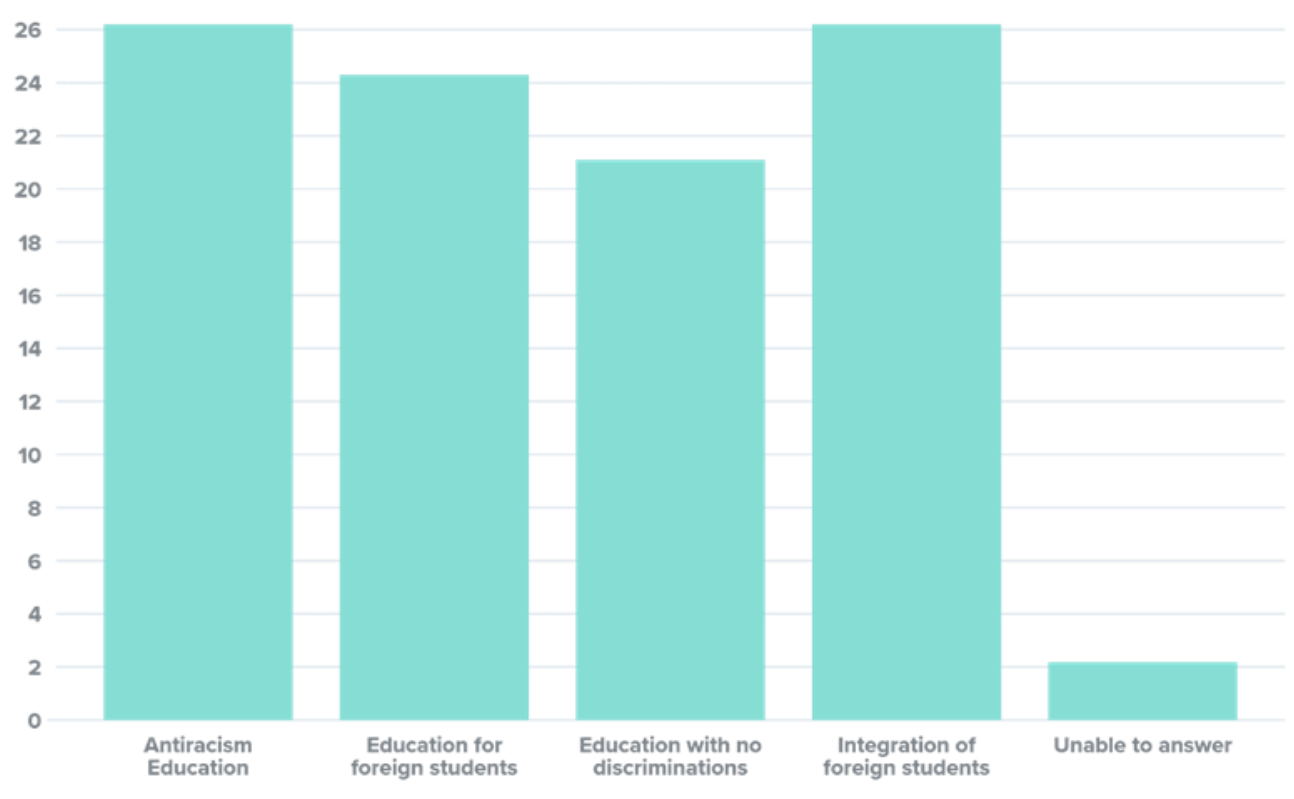

Figure 1. What is Intercultural Education according to you? 
That claim is reinforced by the teachers' judgment, since as shown in graph 2 , they admit that they have not been properly trained to teach in a multicultural class, with $55.2 \%$ of them clearly stating this and $27,4 \%$ stating they have been partially trained. On the other hand, only $17.4 \%$ clearly state that they have received the appropriate training for teaching in a multicultural environment. Undoubtedly, the existing intercultural educational policy is also responsible for this fact, since no formal training is provided to teachers on these issues.

\section{I have been properly trained to teach in a multicultural classroom}

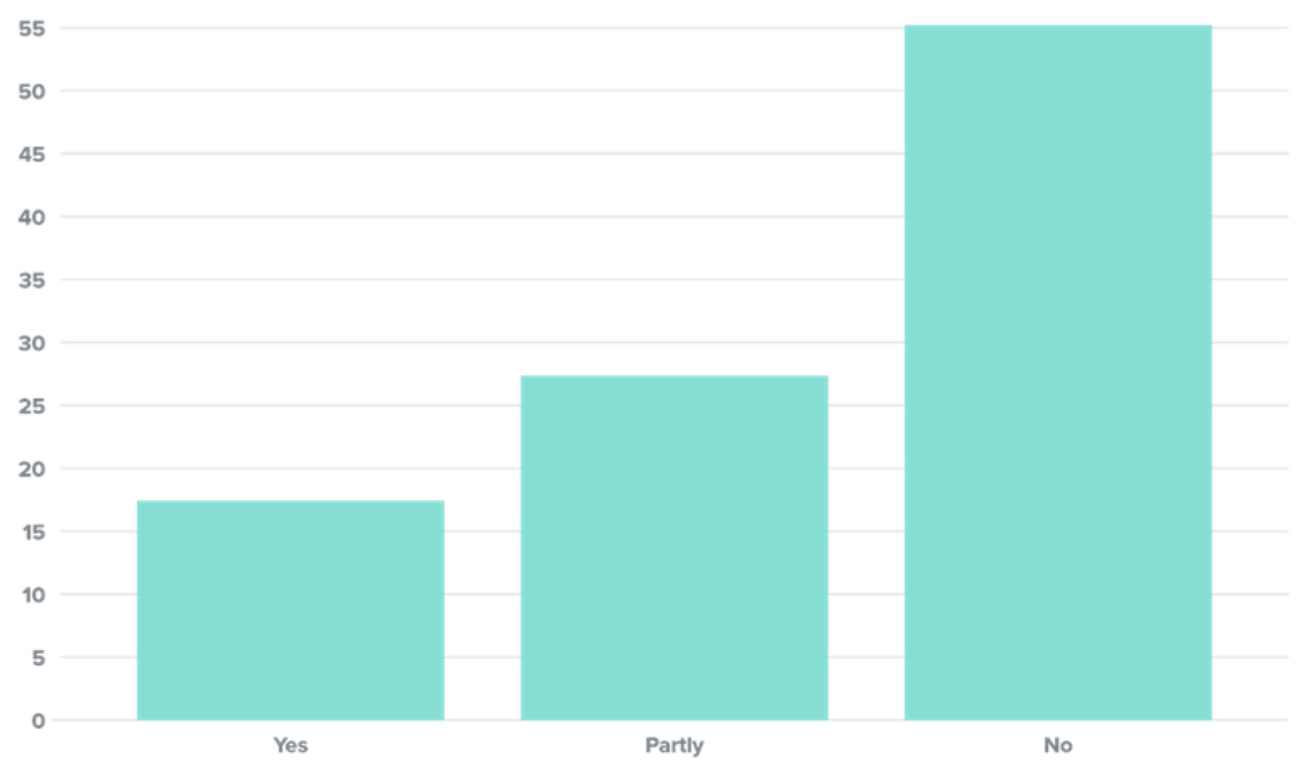

Figure 2. I have been properly trained to teach in a multicultural classroom

This policy is evident from the content of the curricula and school textbooks. As shown in graph 3 , we asked the teachers about them and whether they think that their content corresponds to the multicultural classes. The majority consider that they do not respond at all, with a percentage of $60 \%$, while $35.4 \%$ commented as inadequate the extent to which curricula and school textbooks can respond to classes with children from different ethnic, linguistic and cultural backgrounds. Only $4.4 \%$ of teachers believe that they respond well enough to the multicultural classes, while only $0.2 \%$ of the samples believe that they respond well. These findings prove that the dominant educational policy in our country for multiculturalism does not enjoy the appreciation of the teachers themselves and clearly does not correspond to the multicultural reality that prevails today in the country. In fact, as it is evident from graph 4 , the teachers themselves prioritized the curriculum as the biggest obstacle in the effort of implementing intercultural education. In fact, almost an equal percentage on this scale, gave in the absence of encouragement to engage in intercultural education by the authorities. Both of these factors are directly related to the prevailing educational policy that teachers are called upon to implement in their teaching. Thus, in this way, the teachers point out the fact that since the Curricula, school textbooks and the general educational policy of the Greek state lack references to multiculturalism and therefore the suggestion for the implementation of intercultural education, it is difficult or even impossible at the same time to put into practice the principles of intercultural education and to teach through an intercultural perspective. Indicative of all the above is the fact that the majority of respondents prefer the History lesson material to be quite different from what they teach at the moment. 
International Journal of Education (IJE) Vol.9, No.4, December 2021

\section{curriculum and textbooks correspond to multicultural classes}

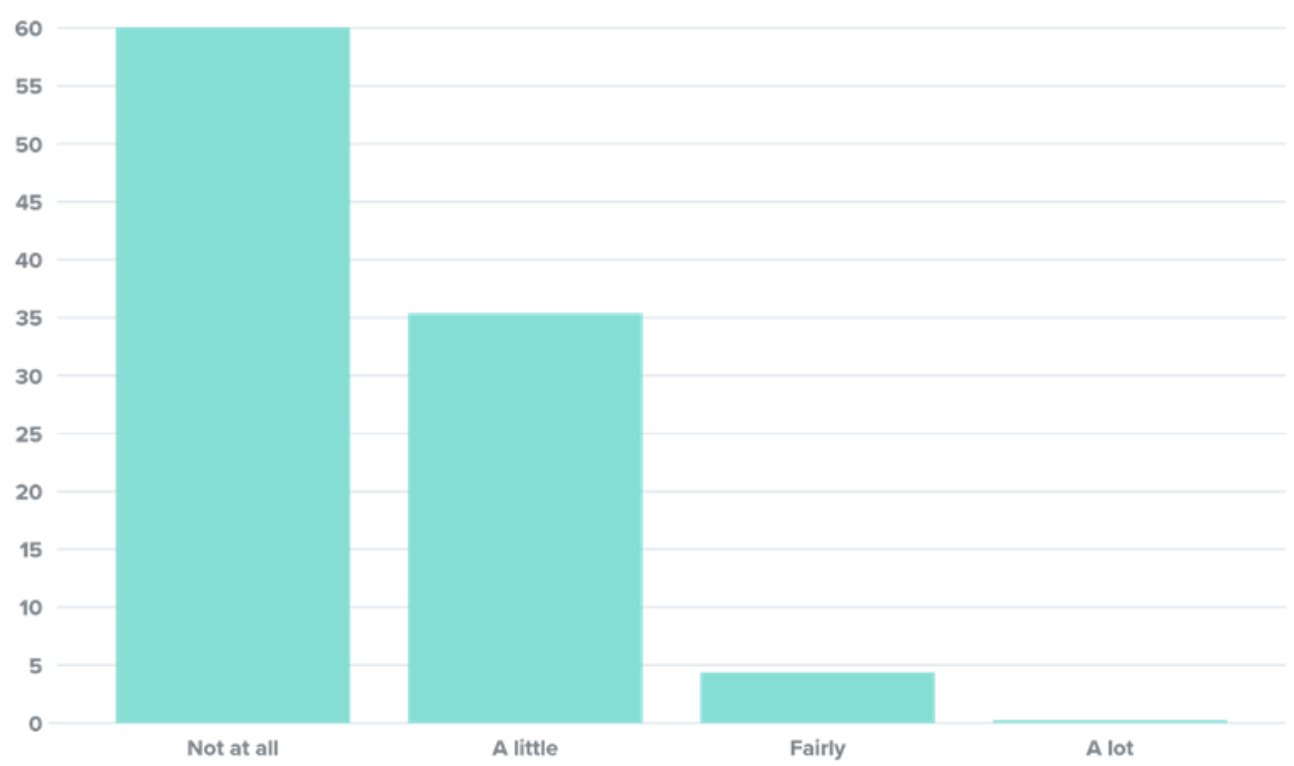

Figure 3. Curriculum and textbooks correspond to multicultural classes

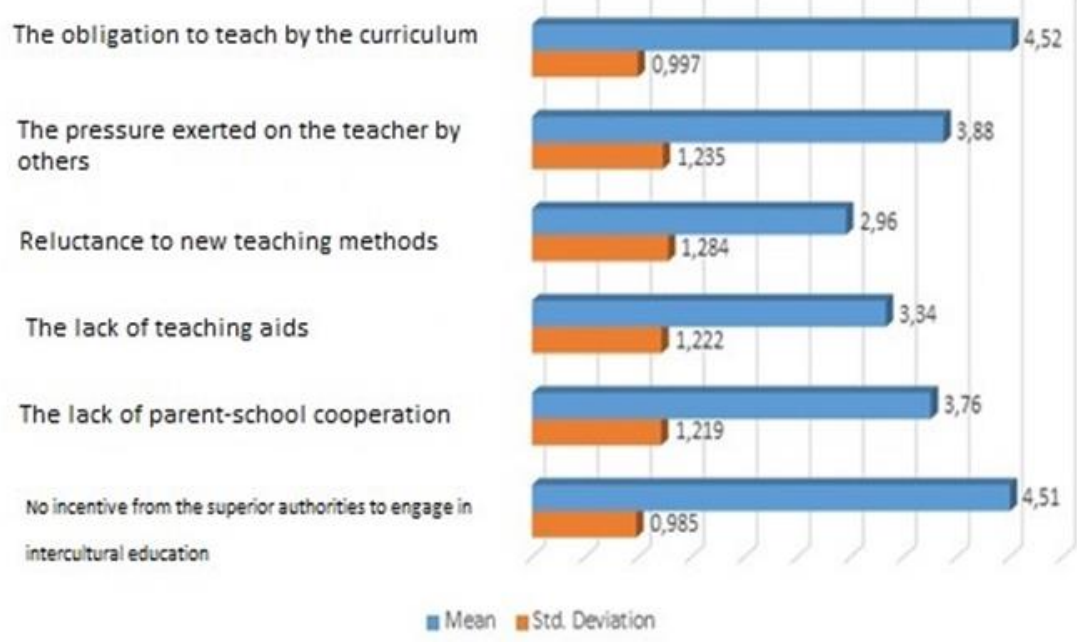

Figure 4. Obstacles in the effort of implementing intercultural education

More specifically, as can be seen from graph 5, the teachers consider that the content of the school History material should first include Local History (4.19), but also be divided among Greek, Balkan, European and World History (4.10). 
International Journal of Education (IJE) Vol.9, No.4, December 2021

\section{Graph 5: School History Curriculum}

Exclusively greek history

Mainly greek history, but also european and world history

Divided between greek, balkan, european and world history

Mainly european and world history

To include local history

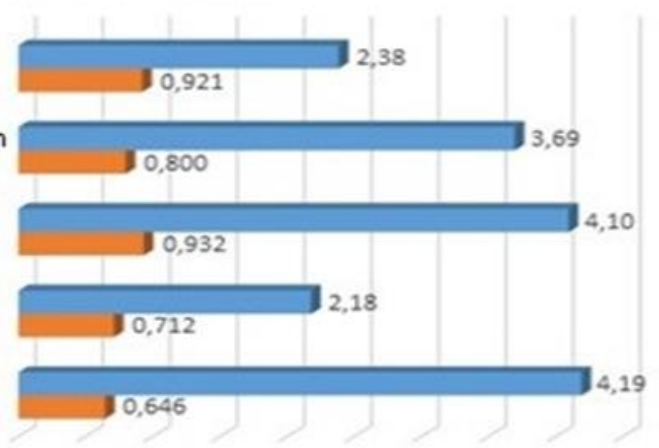

$=$ Mean $=$ Std. Deviation

Figure 5. School History Curriculum must include

Regarding the local history and more specifically the multicultural history of Thessaloniki, the following is observed: as shown in graph 6 in the hypothetical teaching scenario of a Local History program of Thessaloniki, the vast majority of teachers $(93.95 \%)$ would choose to include the multicultural history of the city, too.

\section{In case you would implement a program of local history of Thessaloniki, would you choose to deal with the multicultural past of the city?}

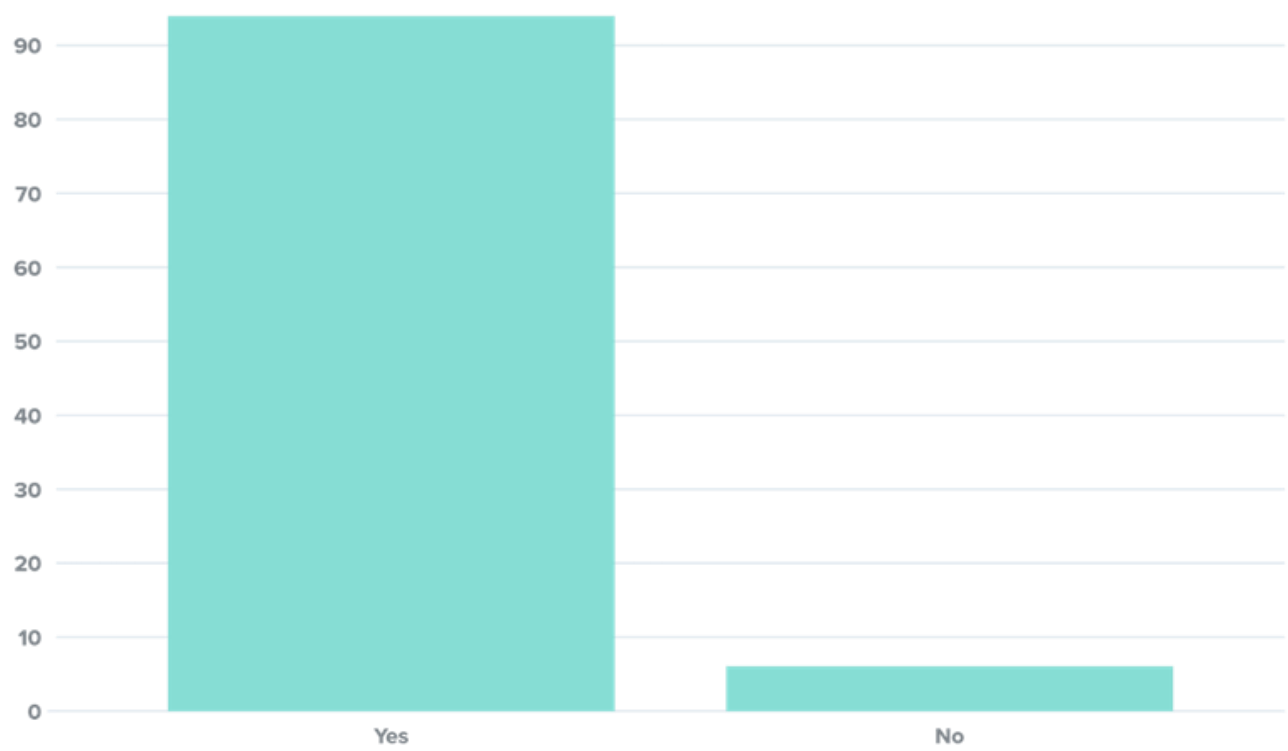

Figure 6. In case you would implement a program of local history of Thessaloniki, would you choose to deal with the multicultural past of the city?

But when they were asked if they are willing in practice to implement a Local History program on the multicultural history of the city and in this case from the vast majority that occurred in the hypothetical event, those willing in practice are slightly more than half with a percentage of 66 , 
$59 \%$, while $33.41 \%$ say no to this possibility. Of course, it is no coincidence that while almost all teachers described the multicultural history of Thessaloniki as important, in practice they are reluctant to implement such a program.

\section{Are you willing to implement a program of local history on the multicultural history of the city?}

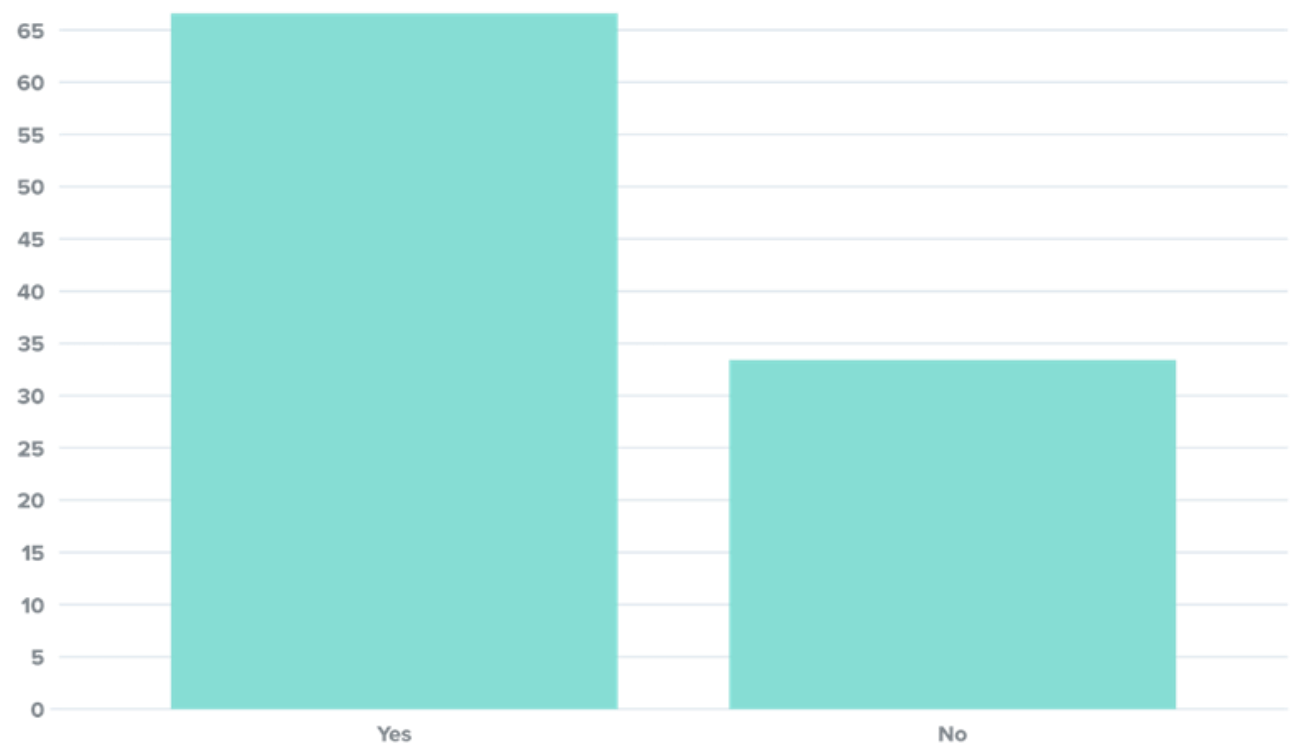

Figure 7. Are you willing to implement a program of local history on the multicultural history of the city?

In the discussion about the reasons that keep teachers reluctant to teach the multicultural history of Thessaloniki, the following graph is enlightening, according to which the issues that concerned us earlier regarding the educational policy are confirmed. In particular, the respondents mention as the main obstacles in the teaching of the multicultural history of Thessaloniki: its absence from the school textbook and the curriculum as well as practical difficulties. Regarding the school material, it is important to clarify that teachers are obliged to complete the curriculum given by the Ministry of Education and Religious Affairs in their teaching during a school year. At the same time, the educational process is required to be in line with the curriculum published by ministerial decision for each course, as well as for the corresponding course of History, in which the purpose of teaching the course, the teaching units with axes of cognitive content, objectives and indicative activities are described in detail. In addition, the practical reasons are mentioned, obviously referring to the lack of time, since, as mentioned before, teachers are primarily called upon to complete the teaching of the historical issues mentioned in the curriculum. Finally, according to the respondents, the fact that the appropriate supervisory material is not provided is also an obstacle to the teaching of the multicultural history of Thessaloniki. Thus, the first four reasons stated by teachers as obstacles have to do with the existing institutional framework in Primary Education and in many cases, as it is obvious, they are kept captive and limited to passively apply the central educational policy. 


\section{If not, it is because:}

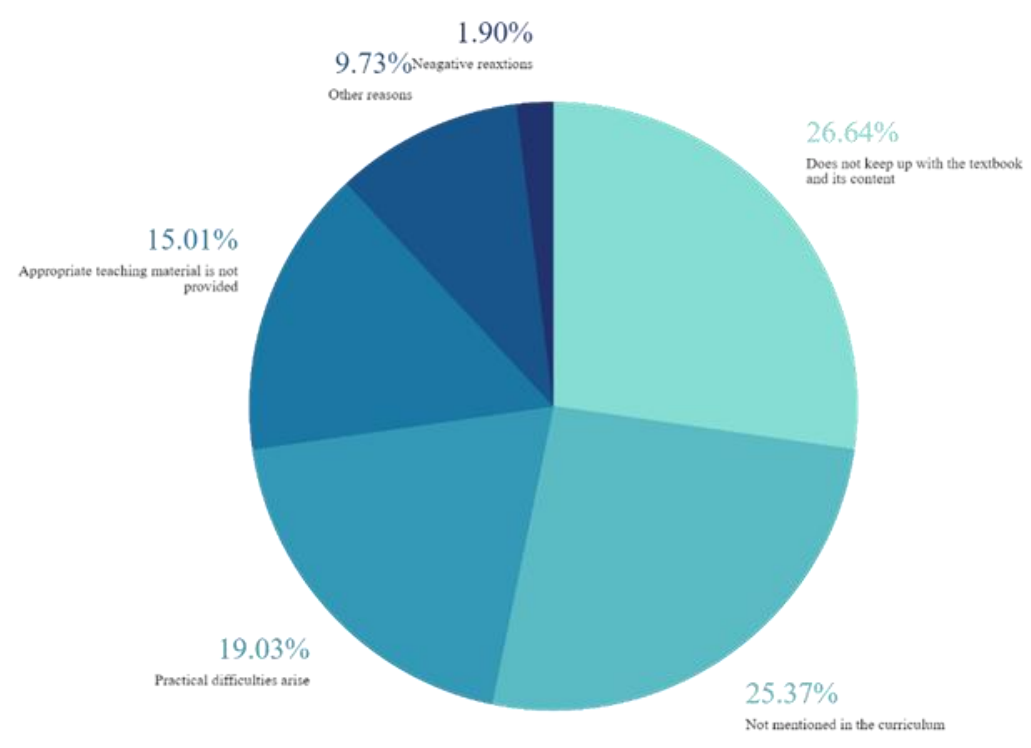

Figure 8. If not, it is because

\section{Conclusions}

In conclusion, taking into account the results of the present research, we can formulate the following conclusions. Initially, the whole sample of teachers finds it quite difficult to identify intercultural education, expressing views that are not related to the fundamental principles of intercultural education as described in the international and Greek bibliography. In fact, half of the teachers surveyed identified intercultural education with corresponding perceptions, with beliefs of non-essential acceptance of foreign and non-foreign children. This conclusion is reinforced by the teachers' own admission that they have not been properly trained to teach in a multicultural classroom. Thus the teachers' training is considered incomplete with regard to the integration of interculturalism and in general the inclusion of contemporary social and cultural issues. Therefore, a well-established systematic and continuous training of teachers in matters of interculturalism is considered necessary, so that they are informed, gain new knowledge and insights, so that they are able to support and promote through history teaching, the rejection of stereotypes, the fight against discrimination and the inclusion of all students with mutual respect. In fact, through the results of previous research analyzed above, too, it appears that teachers after intercultural education programs, formed more progressive perceptions of multiculturalism and applied alternative teaching methods and intercultural education issues. (Luft, 1997, Winitzky \& Barlow, 1998, HO, 2001, DeJaeghere \& Cao, 2009, Sales, Traver, \& García, 2011). Also, through the research findings we find out that the teachers point strongly that the Curriculum, the school textbooks and their obligation of completing the Curriculum, limit the possibilities of applying differentiated teaching and multicultural content during the History lesson. This assumption made by teachers partly explains the research findings of Huang et al. (2017) where while teachers have a positive opinion about intercultural education, during educational practice they do not apply it. It is becoming clear that the institutional framework of education and the dominant educational policy functions as a deterrent to the effort of implementing intercultural 
education. It turns out that not only is there a lack of a comprehensive plan for managing multiculturalism in schools, but also the existing policy limits teachers' teaching and learning practice within a specific context, not allowing them to be flexible according to particular abilities and needs their class and their students may have. In fact, this conclusion is in full accordance with the conclusions of related previous researches, in which even then the primary school teachers characterized the national curriculum as an obstacle and a serious constraint in the implementation of their educational work (Govaris \& Andreadakis, 2002, Patinari, 2015). Besides, it is proposed that the state make further changes, which will respond better to the multicultural reality of the Greek school, enabling teachers to act in accordance with the everchanging needs of their students. It becomes clear that in order for teachers to implement Intercultural Education in practice, it is essential to have the commitment, motivation and readiness of the state for this change, reassuring their concerns and anxieties and emphasizing the need for intercultural understanding and cooperation. In this context, there is also the necessity of utilizing the local, oral, family history and versions of historical education which offer many opportunities so as to integrate the main pillars of Intercultural Education about equality, justice and mutual respect, forming in this way a new school culture.

\section{ACKNOWLEDGEMENTS}

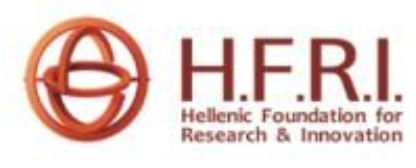

The research work was supported by the Hellenic Foundation for Research and Innovation (HFRI) under the HFRI PhD Fellowship grant (Fellowship Number: 974)

\section{CONFLICT OF INTEREST STATEMENT}

The authors confirm there are no conflict of interest involve with any parties in this research studies.

\section{REFERENCES}

[1] Atiles, J. T., Douglas, J. R., \& Allexsaht-Snider, M. (2017). Early childhood teachers' efficacy in the US rural Midwest: teaching culturally diverse learners. Journal for Multicultural Education, 11(2), 119-130.

[2] Au, W. (2017). When multicultural education is not enough. Multicultural Perspectives, 19(3), 147150.

[3] Bell, J. (2001). Methodological design of pedagogical and social research. Athens: Gutenberg.

[4] Chorozoglou, A. (2011). Discrimination in a multicultural primary classroom. A comparative study of the education system of Greece and Portugal. Lisbon: European Inter - University Center for Human Rights and Democratization.

[5] DeJaeghere, J., \& Cao, Y. (2009). Developing U.S. teachers' intercultural competence: Does professional development matter?, International Journal of Intercultural Relations, 33, 437-447.

[6] Garmon, M.A., (1998), Preservice teachers' learning about diversity: The influence of their existing racial attitudes and beliefs, 1998-10-17, N/A (from Eric data base, www.eric.ed.gov, 19/8/2006, ED425161).

[7] Gkovaris, H. \& Andreadakis, N. (2002). Attitudes of primary education teachers, Educational Sciences, 4/2002, 45-56.

[8] Home Office. (2001). Community Cohesion: A Report of the Independent Review Team (The Cantle Report). London: HMSO. 
[9] Huang, H., Cheng, Y., \& Yang, C. (2017). Science Teachers' Perception on Multicultural Education Literacy and Curriculum Practices, EURASIA Journal of Mathematics Science and Technology Education 2017, 13(6): 2761-2775.

[10] Igglesi, H. (1997). "Let's go again to some streets of our grandparents, of the ancient ancestors": The fear of national alteration in the speech of teachers. Conclusions of the pilot interviews. In A. Fragkoudaki \& T. Dragona (eds.), "What is our homeland?" Ethnocentrism in education, (323-343). Athens: Alexandreia.

[11] Kyriazi, N. (1999). Sociological Research. Athens: Greek letters.

[12] Luft, J., (1997), Learning to teach in a diverse setting: a case study of a multicultural science education enthusiast, 1997-03-21, N/A, (from Eric data base, www.eric.ed.gov, 19/08/2006, ED417143).

[13] Nikolaou, G. (2000). Integration and education of foreign students in primary school: From "homogeneity" to multiculturalism. Athens: Greek letters.

[14] Nikolaou, G. (2003). The Greek teacher towards the problems of integration and education of students with cultural peculiarities, through the eyes of school counselors, In E. Tressou \& S. Mitakidou, Teachers talk to teachers about their experiences, Education of linguistic minorities, (pp. 180-192), Thessaloniki: Observer.

[15] Patinari, F. (2015). Intercultural Education and History Teaching: Teachers' Perceptions on an Intercultural Approach to School History, International Association for Intercultural Education (IAIE) - Conference: Cultural Diversity, Equity and Inclusion : Intercultural Education in the 21st Century and Beyond. Ioannina, 29th June - 3rd July 2015.

[16] Pérez, E., Gómez, M. E. \& Serrano, R. (2017). CLIL Teachers' Perceptions of Intercultural Competence in Primary Education [Percepciones del profesorado AICLE sobre la competencia intercultural en EducaciónPrimaria]. Revista Digital de Investigación en Docencia Universitaria, 11(1), 82-99.

[17] Polat, S., \& Metin, M. (2012). The Relationship Between the Teachers' Intercultural Competence Levels and the Strategy of Solving Conflicts, Procedia - Social and Behavioral Sciences, 46 ( 2012 ), $1961-1968$.

[18] Reyna, C. (2000). Lazy, Dumb or industrious: When stereotypes convey attribution information in the classroom. Education Psychology Review, 12 (1), 86-110.

[19] Sales, A., Traver, J. A., \& Garcia, R. (2011). Action research as a school-based strategy in intercultural professional development for teachers. Teaching and Teacher Education, 27(5), 911919.

[20] Samanta, A., Angelopoulou, P. \& Manesis, N. (2019). The training motivations of teachers to address the needs of bilingual students in primary school. Panhellenic Conference of Educational Sciences, 1 , 1149-1163.

[21] Tremblay, A. (2019). Diversity in Decline? The Rise of the Political Right and the Fate of Multiculturalism. Cham, Switzerland: Palgrave Macmillan.

[22] Vamvoukas, M. (1991). Introduction to Psychopedagogical Research and Methodology. Athens: Grigoris.

[23] Verma, G.K. \& Mallick, K. (2004). Educational Research. Athens: Tipothito.

[24] Winitzky, N. \& Barlow, L., (1998), Changing teacher candidates' beliefs about diversity, 1998-0400, N/A (from Eric data base, www.eric.ed.gov, 19/08/2006, ED419781).

\section{AUTHORS}

Charis Nikolaidou: Teacher at a primary school and PhD candidate at Aristotle University of Thessaloniki

Maria Repoussi: Professor of History and History Education at the Aristotle University of Thessaloniki. 
International Journal of Education (IJE) Vol.9, No.4, December 2021 